\title{
İNFAZ KURUMLARINDAKİ HÜKÜMLÜ SAYISINDAKİ ARTIŞ SORUNU VE ÇÖZÜM ÖNERISII
}

\author{
İzzet ÖZGENÇ* \\ İhsan Yılmaz BAYRAKTARLI**
}

$\ddot{O} Z$

Türkiye'de ceza infaz kurumlarında bulunan hükümlü saylsındaki artış, süreklilik arz eden bir soruna dönüşmüştür. Bu sorunun çözümü için, zaman zaman değişik adlarla çeşitli kanuni düzenlemeler yapılmış ise de, bu düzenlemelerin mahiyeti itibarıly geçici olmast ve sorunu bilimsel olarak ele alan bir yaklaşımın ürünü olmamast sebebiyle, sorun aktüalitesini hiç yitirmemişstir. Çalışmada, infaz kurumlarının kapasitesi ve doluluk durumu ile ilgili istatistiki bilgileri karşılaştırmalı olarak bir değerlendirmeye tabi tutmak gerekmiştir. Kalıca bir çözüm için, Türk ceza hukukunda suç karşılı̆̆ında öngörülen yaptırımların infaz rejimlerinin bir bütün olarak ele alınıp yeniden düzenlenmesi gerekmektedir. Mevzuatımızda, infaz aşamasında ve hatta hüküm kesinleştikten sonra hükümlünün etkin pişmanliktan yararlanılabilmesini ve özellikle hükümlü ile mağdurun barlşmasını sağlayacak yollar tamamen kapalı tutulmuştur. Oysa infaz aşamasında da bu yolların açık tutulması gerekmektedir.

Anahtar Kelimeler: Hapis cezası, Hükümlü, İnfaz, İnfaz kurumu, Koşullu salıverilme, Denetimli serbestlik.

\section{THE PROBLEM OF INCREASE IN THE NUMBER OF INMATES IN CORRECTIONAL FACILITIES AND A PROPOSAL FOR SOLUTION}

\section{ABSTRACT}

Increase in the number of inmates in Correctional Facilities in Turkey has evolved into a continuous problem. Despite several attempts at dealing with this issue via legislative initiatives under different titles, the issue never lost its place on the agenda since all the previous attempts proved to be temporary in nature and lacked scientific ground studies beforehand. In this study, statistical data on the capacity of correctional facilities and the occupancy rates were scrutinized form a comparative perspective. In order to achieve a lasting solution, correctional regimes of the sanctions set forth in the Turkish Criminal Law for offences should be reconsidered and reorganized completely. In our current legislation, neither active remorse, nor, in particular, methods of reconciliation between the convicted and the victim is possible during the execution period and even after res judicata. What is required, however, is to keep these options available during the execution period as well.

Keywords: Prison Sentence, Convicted, Execution, Correctional Facility, Conditional Release, Probation

\footnotetext{
* Prof.Dr., Ankara Hacı Bayram Veli Üniversitesi Hukuk Fakültesi Ceza ve Ceza Muhakemesi Hukuku Anabilim Dalı Öğretim Üyesi. e-posta: oezgenc@gmail.com

** Dr.Öğr.Üyesi, Ankara Hacı Bayram Veli Üniversitesi Türk Ceza Hukuku Uygulama ve Araştırma Merkezi Ögretim Üyesi. e-posta: ihsanyb@gmail.com
}

Yayın Kuruluna Ulaştı̆̆ı Tarih $\quad$ : 28.11.2018

Yayınlanmasının Uygun Görüldüğü Tarih : 18.01.2019 
İnfaz Kurumlarındaki Hükümlü Sayısındaki Artış Sorunu Ve Çözüm Önerisi

\section{ANALYSE UND LÖSUNGSVORSCHLÄGE ÜBER DIE ZUNEHMENDE ZAHL DER VERURTEILTEN IN DEN VOLLZUGSANSTALTEN}

\section{ZUSAMMENFASSUNG}

Die zunehmenden Zahlen der Verurteilten in den Strafanstalten in der Türkei haben sich in ein Kontinuumsproblem verwandelt. Um dieses Problem anzugehen, wurde in der Vergangenheit zwar von Zeit zu Zeit verschiedene gesetzliche Regelungen mit unterschiedlichen Namen getroffen, doch da diese Regelungen meist vorübergehend waren und nicht auf einem wissenschaftlichen Ansatz beruhten, hat das Problem von seiner Aktualität nichts verloren. In dieser Studie ist eine vergleichende Bewertung der statischen Informationen über die Kapazität und den Belegungsstatus der Strafanstalten erforderlich. Für eine dauerhafte Lösung sollte im türkischen Strafrecht für das Verbrechen vorgeschriebenen Sanktionen und Vollstreckungsbestimmungen als Ganzes betrachtet und reorganisiert werden. Im türkischen Recht ist es nicht vorgesehen, dass der Verurteilte während der Vollstreckung und selbst nach der Verurteilung von der Kronzeugenregelung (der tätigen Reue) einen Vorteil erzielen kann, der insbesondere zum Frieden zwischen dem Verurteilten und dem Opfer beiträgt. Diese Option sollte jedoch während der Vollstreckung möglich sein.

Schlüsselwörter: Haftstrafe, Verurteilte, Strafvollzug, Vollzugsanstalt, Bedingte Freilassung, Bewährung.

\section{Giriș}

Türkiye'de ceza infaz kurumlarında bulunan hükümlü sayısındaki artış, süreklilik arz eden bir soruna dönüşmüştür. Bu sorunun çözümü için, zaman zaman değişik adlarla çeşitli kanuni düzenlemeler yapılmış ise de, bu düzenlemelerin mahiyeti itibarıyla geçici olması ve sorunu bilimsel olarak ele alan bir yaklaşımın ürünü olmaması sebebiyle, sorun aktüalitesini hiç yitirmemiştir. Sorunun kalıcı bir çözüme kavuşturulabilmesine yönelik normatif bir çalışma öncesinde, infaz kurumlarının kapasitesi ve doluluk durumu ile ilgili istatistiki bilgileri karşılaştırmalı olarak bir değerlendirmeye tabi tutmak gerekmiştir.

II. Londra'da bulunan “Milletlerarası Cezaevi Çalışmaları Merkezi”ne ("International Centre for Prison Studies") ait "www.prisonstudies.org" internet sitesinde yer alan verilere baktığımızda, bugün itibarıyla, nüfusuna oranla, hükümlü veya tutuklu olarak ceza infaz kurumlarında en fazla kişi barındıran ülkenin ABD olduğunu görmekteyiz. ABD'de her 152 kişiden biri, ceza infaz kurumlarında hükümlü veya tutuklu olarak bulunmaktadır.

Bu ülkeyi takip eden devlet Rusya'dır. Bu ülkede her 249 kişiden biri, ceza infaz kurumlarında hükümlü veya tutuklu olarak bulunmaktadır.

Nüfusa oranla hükümlü veya tutuklu olarak infaz kurumlarında bulunan kişi sayısı itibarıyla Türkiye, üçüncü sırada yer almaktadır. Türkiye'de her 347 kişiden biri, ceza infaz kurumlarında hükümlü veya tutuklu olarak 
bulunmaktadır. Türkiye'yi takip eden Devlet, İran'dır. İran'da her 352 kişiden biri, ceza infaz kurumlarında hükümlü veya tutuklu olarak bulunmaktadır.

Nüfusa oranla hükümlü veya tutuklu olarak infaz kurumlarında bulunan kişi sayısı itibarıyla dünyanın en iyi ülkesi Japonya'dır. Bu ülkede her 2.439 kişiden biri, ceza infaz kurumlarında hükümlü veya tutuklu olarak bulunmaktadir.

Yaptırım sistemi ve en azından teorik açıdan izlediği infaz siyaseti bakımından Türkiye'nin örnek aldığı devletlerdeki durum şu şekildedir:

Almanya: Bu ülkede her $\mathbf{1 . 3 3 3}$ kișiden biri, ceza infaz kurumlarında hükümlü veya tutuklu olarak bulunmaktadır.

İtalya: $\mathrm{Bu}$ ülkede her $\mathbf{1 . 0 2 0}$ kişiden biri, ceza infaz kurumlarında hükümlü veya tutuklu olarak bulunmaktadır.

Fransa: $\mathrm{Bu}$ ülkede her 961 kişiden biri, ceza infaz kurumlarında hükümlü veya tutuklu olarak bulunmaktadır.

Güney Kore: Bu ülkede her 917 kişiden biri, ceza infaz kurumlarında hükümlü veya tutuklu olarak bulunmaktadır.

İngiltere: $\mathrm{Bu}$ ülkede her $\mathbf{7 1 4}$ kişiden biri, ceza infaz kurumlarında hükümlü veya tutuklu olarak bulunmaktadır.

Çin ve Suudi Arabistan, ceza infaz kurumlarında bulunan hükümlü ve tutuklularla ilgili bilgileri gizli tutmaktadır. $\mathrm{Bu}$ ülkelerdeki hükümlü ve tutukluların sayısına ilişkin bilgiler gayri resmi kaynaklara dayandığ 1 için, değerlendirmede dikkate alınmamıştır. Keza, Mısır'la ilgili verilerin, değerlendirmelerimizde esas alınacak ölçütleri taşımadığı gözlemlenmiştir.

III. Türkiye, bütün bu örnek ülkeler arasında, ceza infaz kurumlarında, hükümlülere nazaran tutuklu olarak en fazla kişi bulunduran devlettir.

Bu sitede yayımlanan verilere göre, Türkiye' de ceza infaz kurumlarında bulunan tutukluların oranı, mevcuda nazaran 31.12.2017 tarihi itibarıla \% 43,1'dir.

Örnek alınan devletler arasındaki sıralama şu şekildedir:

Japonya: \% 10,8.

İngiltere: $\% 11,2$.

Rusya: \% 17,5.

ABD: $\%$ 21,6.

Almanya: \% 22,6.

İran: \% 25,1. 
Fransa: \% 29,7.

İtalya: $\% 33,3$.

Güney Kore: \% 34,5.

IV. Bu sitedeki verilere göre, söz konusu örnek ülkeler arasında infaz kurumlarının doluluk oranı itibarıyla sıralama şu şekildedir:

Japonya: \% 66,8 (31.3.2018 tarihi itibarıla).

Rusya: \% 79 (? tarihi itibarlyla).

Almanya: \% 84,8 (31.3.2018 tarihi itibarıla).

ABD: \% 103,9 (2014 y1l itibarıla).

İngiltere: \% 109,4 (29.6.2018 tarihi itibarıla).

Türkiye: \% 111,5 (1.1.2018 tarihi itibarıla).

Güney Kore: \% 115,4 (31.3.2018 tarihi itibarıyla).

İtalya: \% 116,8 (31.8.2018 tarihi itibarıla).

Fransa: \% 118,4 (1.7.2018 tarihi itibarıla).

İran: \% 161,2 (113.2018 tarihi itibarıla).

V. Ülkelerin ceza infaz kurumlarının kapasitesinin nüfuslarına göre sıralaması şu şekildedir:

\section{Japonya:}

Nüfusu 126 milyon 510 bin kişi (2018 Temmuz sonu itibarıyla)

İnfaz kurumlarının kapasitesi, 90.536 kişi (31.12.2014)

Buna göre, Japonya'da her $\mathbf{1 . 3 9 7}$ kişiye infaz kurumlarında bir kişilik yer tekabül etmektedir.

İtalya:

Nüfusu 60 milyon 410 bin kişi (2018 Ağustos sonu itibarıla)

İnfaz kurumlarının kapasitesi, 50.622 kişi (31.8.2018)

Buna göre, İtalya'da her $\mathbf{1 . 1 9 3}$ kişiye infaz kurumlarında bir kişilik yer tekabül etmektedir.

\section{Fransa:}

Nüfusu 67 milyon 800 bin kişi (2018 Temmuz başı itibarıyla)

İnfaz kurumlarının kapasitesi, 59.703 kişi (1.7.2018) 
Buna göre, Fransa'da her $\mathbf{1 . 1 3 5}$ kişiye infaz kurumlarında bir kişilik yer tekabül etmektedir.

\section{Almanya:}

Nüfusu 82 milyon 930 bin kişi (2018 Mart sonu itibarıla)

İnfaz kurumlarının kapasitesi, 73.336 kişi (31.3.2018)

Buna göre, Almanya'da her $\mathbf{1 . 1 3 1}$ kişiye infaz kurumlarında bir kişilik yer tekabül etmektedir.

\section{Güney Kore:}

Nüfusu 50 milyon 800 bin kişi (2017 sonu itibarıla)

İnfaz kurumlarının kapasitesi, 47.820 kişi (31.12.2017)

Buna göre, Güney Kore'de her $\mathbf{1 . 0 6 2}$ kişiye infaz kurumlarında bir kişilik yer tekabül etmektedir.

\section{İngiltere:}

Nüfusu 59 milyon 200 bin kişi (2018 Eylül sonu itibarıyla)

İnfaz kurumlarının kapasitesi, 75.859 kişi (29.6.2018)

Buna göre, İngiltere'de her $\mathbf{7 8 0}$ kişiye infaz kurumlarında bir kişilik yer tekabül etmektedir.

İran:

Nüfusu 80 milyon 910 bin kişi (2017 Haziran itibarıyla)

İnfaz kurumlarının kapasitesi, 140.000 kişi (2014 Aralık itibarıyla)

Buna göre, İran'da her 577 kişiye infaz kurumlarında bir kişilik yer tekabül etmektedir.

\section{Türkiye:}

Nüfusu 80 milyon 890 bin kişi (2018 başı itibarıyla)

İnfaz kurumlarının kapasitesi, 208.780 kişi (1.1.2018)

Buna göre, Türkiye'de her $\mathbf{3 8 7}$ kişiye infaz kurumlarında bir kişilik yer tekabül etmektedir.

\section{Rusya:}

Nüfusu 144 milyon 900 bin kişi (2018 Eylül başı itibarıyla)

İnfaz kurumlarının kapasitesi, 812.804 kişi (1.10.2015) 
Buna göre, Rusya' da her 178 kişiye infaz kurumlarında bir kişilik yer tekabül etmektedir.

\section{ABD:}

Nüfusu 323 milyon 900 bin kişi (2016 sonu itibarıyla)

İnfaz kurumlarının kapasitesi, 2.140.321 kişi (2014 itibarıyla)

Buna göre, ABD'de her 151 kişiye infaz kurumlarında bir kişilik yer tekabül etmektedir.

Türkiye ile nüfusu birbirine yakın ülke olarak birbiriyle karşılaştırıldığında görülmektedir ki, Almanya'da 31.3.2018 tarihi itibarıyla infaz kurumlarında bulunan tutuklu ve hükümlü sayısı toplamı 62.194'tür. Türkiye'de ise, bu say1 1.1.2018 tarihi itibarıyla 232.886'dır. Keza, Almanya'daki tutuklu ve hükümlülerin 31.3.2015 tarihi itibarıyla \% 31,3'ü (Alman vatandaşı olmayan) yabancıdır. Buna karşılık Türkiye' de ise bu oran, 1.9.2016 tarihi itibariyla \% 2,2' dir $^{1}$.

Bütün bu verilerden hareketle şu sonuca varmaktayı: Türkiye'deki infaz kurumlarında bulunan hükümlü ve tutuklu sayısının azaltılmasında izlenecek infaz siyasetiyle, infaz kurumlarının mevcudunun ve hatta, kapasitesinin düşürülmesinin sağlanması gerekmektedir.

VI. Türkiye' de infaz kurumlarında bulunan hükümlü sayısında tarihsel süreç içinde artış gözlemlenmektedir. Bu artışlar sebebiyle infaz kurumlarının kapasitesinin üzerine çıkılması karşısında, çözüm olarak önceleri genel af ve bilahare özel koşullu salıverilme kanunlarıyla kurumların tahliyesi yoluna gidilmiştir. Ancak, bu tahliyeler ancak geçici bir süre için "çözüm" oluşturabilmiştir.

Örneğin 31 Aralık 1999 tarihi itibarıyla infaz kurumlarında bulunan hükümlü sayısı 44.131 iken, 22.12.2000 tarihli ve 4616 sayılı Kanunla gerçekleştirilen koşullu salıverilmeler üzerine bu sayı 31 Aralık 2000 tarihi itibarıyla $\mathbf{2 4 . 8 5 5}$ 'e inmiştir. Ancak, 31.12.2003 tarihi itibarıyla infaz kurumlarında bulunan hükümlü sayısı tekrar 37.056'ya yükselmiştir.

5237 sayılı Türk Ceza Kanununun 1 Haziran 2005 tarihinde yürürlüğe girişi dolayısıyla lehe kanun uygulamaları bağlamında infazın durdurulması (5252 s. TCK Yürürlük Kanunu, m. 10) yoluna gidilmek suretiyle, infaz kurumlarından tahliyeler gerçekleşmiş olmasına rağmen, infaz kurumlarındaki

\footnotetext{
${ }^{1}$ İşaret etmek gerekir ki, İsrail'de nüfusun her 429 kişiden birisi hükümlü veya tutuklu olarak ceza infaz kurumlarında bulunmaktadır. Ancak, 31.12.2014 tarihi itibarıyla İsrail ceza infaz kurumlarında bulunan Filistinlilerin oranı, toplam tutuklu ve hükümlülerin 38,9'udur.
} 
hükümlü sayısında sürekli bir yükseliş gözlemlenmiştir:

Ceza infaz kurumlarında,

2005 yılı sonu itibariyla 29.445,

2011 yılı sonu itibarıyla 92.617,

hükümlü bulunmakta idi.

Yeni Türk Ceza Kanununda, suçların karş1lığında öngörülen cezalar, mülga 765 sayılı TCK'ya nazaran çok daha yüksektir. Keza, mülga 765 sayılı TCK'nın sisteminde kişi mahkum olduğu hapis cezasının beşte ikisini infaz kurumunda iyi halli olarak çektiği takdirde koşullu salıverilmeden yararlanabilmekte idi. Buna karşılık yeni TCK'nın sisteminde ise, ilk defa suç işlemiş olan kişi mahkum olduğu hapis cezasının infazı sürecinde koşullu salıverilmeden yararlanabilmesi için mahkum olduğu cezanın üçte ikisini infaz kurumunda iyi halli olarak çekmesi gerekmektedir. Buna karşılık, mükerrirler ile, terör suçlarından, cinsel suçlardan, uyuşturucu veya uyarıcı madde imal ve ticareti suçlarından mahkum olanlar, cezalarının dörtte üçünü infaz kurumunda iyi halli olarak çektikleri takdirde koşullu salıverilmeden yararlanabilecektir.

Eski Kanunun yürürlükte olduğu dönemde örneğin kasten öldürme suçundan dolayı mahkum olunan hürriyeti bağlayıcı cezanın en fazla 12 yılını infaz kurumunda çektiği takdirde koşullu salıverilmeden yararlanarak tahliye edilebilmekte idi. Buna karşılık, yeni TCK'nın sisteminde ise, kasten öldürme suçundan mahkum olan kişi, 24 yıl infaz kurumunda cezasını çektikten sonra, iyi halli ise, koşullu salıverilmeden yararlanabilmektedir.

Lehe kanun hükümlerinin uygulanması sebebiyle, ancak 2010 ve sonras1 yıllarda yeni TCK hükümlerine göre mahkum olan hükümlülerin infaz kurumuna girdiğini gözlemlemekteyiz. Bu nedenledir ki, 2010 ve sonrasında infaz kurumlarında bulunan hükümlü sayısındaki artış oranı, önceki yıllara nazaran daha yüksektir.

İnfaz kurumlarında bulunan hükümlü sayısı, her ay ortalama $\mathbf{2 . 0 0 0}$ kişi artmaktadır.

Bu sayı, bugün itibarıyla Türkiye'deki infaz kurumlarının kapasitesinin üzerindedir. Bu rakamlara tutuklu sayıları dahil değildir.

İnfaz kurumlarındaki hükümlü sayısındaki artış sorununu çözmeye yönelik olarak, 5275 sayılı İnfaz Kanununa değişik tarihlerde çeşitli hükümler eklenmiştir. 
A) 5.4.2012 tarihli ve 6291 sayılı Kanunla ${ }^{2}$ İnfaz Kanununda değişiklik yapılmıştır. $\mathrm{Bu}$ değişiklikle, mahkum olduğu hapis cezasının önemli bir kısmını infaz kurumunda çeken ve fakat henüz koşullu salıverilme aşamasına gelmemiş olan hükümlülerin cezalarının kalan kısmının denetimli serbestlik tedbiri uygulanarak toplumsal ortamda infazının yolu açılmıştır (İnfaz K. m. 105/A, Geçici madde 3). Bu düzenlemeyle, koşullu salıverilme tarihine bir yıl kala, "denetimli serbestlik tedbiri" uygulamasıyla hükümlünün infaz kurumundan dışarı çıkarılması sağlanmaktadır. Bu değişiklik gereğince, ceza infaz kurumlarından tahliyeler gerçekleşmiştir.

Buna rağmen, infaz kurumlarındaki hükümlü sayısında sadece kısa bir süreliğine bir azalma meydana gelmiş ve hemen akabinde sayı artmaya devam etmiştir.

Şöyle ki, 31.12.2011 tarihi itibarıla infaz kurumlarında bulunan hükümlü sayıs1 92.617 iken; 6291 sayılı Kanunun 11.4.2012 tarihinde yürürlüğe girmesine rağmen, bu sayı 31.12.2012 tarihi itibarıla $\mathbf{1 0 4 . 3 1 3}$ olmuştur.

B) 24.1.2013 tarihli ve 6411 sayılı Kanunla ${ }^{3}$ İnfaz Kanununa yeni bir geçici madde eklenmiştir (Geçici madde 4). Bu geçici madde ile, koşullu salıverilme öncesi denetimli serbestlik tedbirinden yararlanabilmek için cezasının son altı ayının açık ceza infaz kurumunda çekilmesi koşulu kaldırılmış ve bu suretle, İnfaz Kanununun 105/A maddesinin uygulama alanı genişletilmiştir. Bu geçici madde hükmü gereğince, denetimli serbestlik tedbiri uygulanmak üzere ceza infaz kurumlarından tahliyeler gerçekleşmiştir.

$\mathrm{Bu}$ tahliyelere rağmen, infaz kurumlarındaki hükümlü sayısında sadece kısa bir süreliğine bir azalma meydana gelmiş ve hemen akabinde sayı artmaya devam etmiştir.

Şöyle ki, 2013 yılı Ocak ayı itibarıyla infaz kurumlarında bulunan hükümlü sayıs1 106.290 iken; 6411 sayılı Kanunun yürürlüğe girmesi üzerine bu sayı 2013 yılı Şubat ayında 95.002'ye düşmüştür. Ancak bu sayı, tekrar 2013 Temmuz ayı itibarıla 106.562'ye yükselmiş ve 31.12.2013 tarihi itibarıla $\mathbf{1 1 7 . 7 8 5}$ olmuştur.

C) 15.8.2016 tarihli ve 671 sayıl1 KHK (6757 s. Kanun) ile, İnfaz Kanuna "Geçici madde 6" olarak yeni bir "geçici" madde eklenmiştir.

$\mathrm{Bu}$ düzenlemeyle, "Geçici madde 105/A"daki bir yıllık süre iki

\footnotetext{
${ }^{2}$ RG: 11 Nisan 2012/28261.

${ }^{3}$ RG: 31 Ocak 2013/28545.
} 
yıla çıkarılmış ve ayrıca, bu düzenlemeye göre, koşullu salıverilmeden yararlanabilmek için mahkum olunan hapis cezasının yarısını infaz kurumunda çekmek gerekmektedir.

$\mathrm{Bu}$ düzenlemeye rağmen de, infaz kurumlarındaki hükümlü sayısında sadece kısa bir süreliğine bir azalma meydana gelmiş ve hemen akabinde sayı artmaya devam etmiştir.

Şöyle ki, 31.12.2015 tarihi itibarıla infaz kurumlarında bulunan hükümlü sayısı 152.869 iken; 671 sayılı KHK'nın 17 Ağustos 2016 tarihinde yürürlüğe girmesine rağmen, bu sayı tekrar 1.11.2016 tarihi itibarıyla 129.291; 2.10.2017 tarihi itibarıyla $\mathbf{1 4 0 . 2 4 8}$ olmuştur.

$\mathrm{Bu}$ tarihten sonraki istatistiki veriler elimizde bulunmadığı için, 2017 Ekim ayı itibarıyla ortaya çıkan gelişmeleri değerlendirme imkanımız olmamıştır.

Dikkat edilmelidir ki, bu sayıların içinde DÖRT YIL veya daha az süreli hapis cezasına mahkum olmuş olan ya da iki yıl cezaya mahkum edilmiş olmakla beraber cezası ertelenmemiş olan hükümlüler bulunmamaktadır. Başka bir ifadeyle, bu sayılar, mükerrirler ile terör suçlarından, cinsel suçlardan, uyuşturucu veya uyarıcı madde imal ve ticareti suçlarından mahkum olan ve ayrıca, DÖRT YILDAN FAZLA süreyle hapis cezasına mahkum edilmiş olup da infaz kurumunda cezasını çekmekte olan hükümlüleri kapsamaktadır.

Buna rağmen, 2018.11.15 tarihi itibarıla ceza infaz kurumlarında dört yıldan daha az süreyle hapis cezasına mahkum olmuş olan hükümlüler bulunmaktadır ve bunların sayısı oldukça fazladır. Ceza infaz kurumlarında bulunan,

a) Bir yıla kadar hapis cezasına mahkum olan hükümlü sayısı, $\quad \mathbf{7 . 9 6 0}$;

b) Bir yıldan iki yıla kadar hapis cezasına mahkum olan hükümlü say1s1, 7.566;

c) İki yıldan üç yıla kadar hapis cezasına mahkum olan hükümlü say1s1, 11.128;

ç) Üç yıldan dört yıla kadar hapis cezasına mahkum olan hükümlü say1s1, 9.780'dir.

Buna göre, söz konusu tarih itibarıyla ceza infaz kurumlarında dört yıldan daha az süreyle hapis cezasına mahkum olmuş olan hükümlü sayısı toplamı, 36.434'tür. 
Bu durum, İnfaz Kanunu, madde 105/A hükmü gereğince denetimli serbestlik tedbiriyle dışarı çıkarılan hükümlülerden yeniden suç işleyerek infaz kurumuna geri dönenlerin sayısının oldukça fazla olduğunu göstermektedir. Keza, belirtmek gerekir ki, dört yıl veya daha az süreli hapis cezasına mahkum edilmiş olan mükerrirler ile alelıtlak terör örgütü üyeliğinden mahkum olanlar da bu sayının içindedir.

Yapılan bütün bu düzenlemelerle infaz kurumlarındaki yoğunluk, sorun olmaktan çıkarılamamıştır. Zaman içerisinde infaz kurumlarının kapasitesinin artırılması da bu sorunu çözememiştir.

VII. Denetimli serbestlik tedbirinin uygulanması bakımından da alt yapımızda ve uygulamamızda önemli sorunlar bulunmaktadır. Adalet Bakanlığının son yayımlanan istatistiki verilerine göre, denetimli serbestlik ve yardım hizmetleri görevlileri tarafından takip ve denetimi yapılan kişi sayısı 2018 yılı Ağustos ayı itibarıyla toplamda 607.936'dır.

Bunlardan,

a) şüpheli veya sanık olarak hakkında adli kontrol tedbiri uygulanan kişi sayısı, 398.294'tür;

b) uyuşturucu veya uyarıcı madde kullanmak dolayısıyla hakkında denetimli serbestlik tedbiri uygulanan kişi sayısı, 62.628' dir;

c) İnfaz Kanunu, madde 105/A hükmü gereğince, hakkında denetimli serbestlik tedbiri uygulanan kişi sayısı, 99.760'dır;

ç) mükerrir, itiyadi suçlu, suçu meslek edinen kişi, örgüt mensubu suçlu olması sebebiyle hakkında denetimli serbestlik tedbiri uygulanan kişi sayısı, 11.812'dir.

Dikkat edilmelidir ki bu toplam sayı, hakkında hükmün açıklanmasının geri bırakılması kararı verilen sanıklarla koşullu salıverilen hükümlüleri kapsamamaktadır.

Bugün itibarılya, denetimli serbestlik hizmetlerinin gerek teşkilat ve gerekse personel donanımı, etkin bir denetimli serbestlik hizmeti vermeye elverișli değildir. Bu nedenledir ki, hakkında formel olarak denetimli serbestlik tedbiri uygulansa bile, ceza infaz kurumundan çıkarılan hükümlü, kısa bir zaman sonra yeniden suç işleyerek infaz kurumuna geri dönmektedir ${ }^{4}$.

\footnotetext{
${ }^{4}$ Bu konularda ayrıntılı bilgi için bkz. ÖZGENÇ, İzzet: "Die aktuellen Probleme in der Praxis des Türkischen Strafvollstreckungsrechts", in: Dr.Dr.h.c. Silvia Tellenbach'a Armağan, Editörler: F. Yenisey, İ. Özgenç, A. Nuhoğlu, A. Sözüer, F. Turhan, Ankara, Mayıs 2018, sh. 1177 vd.; ÖZGENÇ, İzzet: Türk Ceza Hukuku Genel Hükümler, 14. bası, Ankara, Ağustos
} 


\section{Sonuç ve Önerimiz}

Acil önerimiz, Türk ceza hukukunda suç karşı1lı̆̆ında öngörülen yaptırımların infaz rejimlerinin bir bütün olarak ele alınıp yeniden düzenlenmesinin sağlanmasıdır.

Kalıcı çözümler oluşturmadığımız sürece, kısa bir zaman zarfında, yine aynı sorunu aktüel olarak yaşamaya mahkûmuz.

Kalıcı çözüm oluşturulabilmesi için, kapsamlı bir çalışma yapılması gerekmektedir. $\mathrm{Bu}$ konuda yapılan akademik çalışmalarda oluşturulan önerilerin hayata geçirilebilmesi için, Adalet Bakanlığı istatistiklerinde yayımlanmayan, hükümlü ve tutuklulara ilişkin bazı verilerin ilgililerle paylaşılması gerekmektedir.

Sistemimizde, infaz aşamasında ve hatta hüküm kesinleştikten sonra hükümlünün mağdurla ilişkisi tamamen kesilmektedir. Oysa infaz aşamasında da etkin pişmanlıktan yararlanılabilmesinin ve özellikle hükümlü ile mağdurun barışmasını sağlayacak yolların açık tutulması gerekmektedir. Halen cari infaz sistemimizde bu yollar tamamen kapalıdır.

Ancak, bu yolların işletilebilmesi için mahkemelerin iş yükümün de artırılmaması gerekmektedir.

$\mathrm{Bu}$ yöntemle, özellikle cinsel suçlardan mahkum olan faille mağdur arasında bilahare meşru zeminde evliliğin gerçekleşmesine rağmen, infaza devam edilmesinin ortaya çıkardığı şikayetlerin de sonlandırılması mümkün bulunmaktadır.

2018, sh. $826 \mathrm{vd}$. 